\title{
Enhancing flood risk system robustness in practice
}

\author{
M.J.P. Mens \\ Deltares, Delft, the Netherlands \& Twente University, Enschede, the Netherlands \\ F. Klijn \\ Deltares, Delft, the Netherlands
}

R. Schielen

Twente University, Enschede, the Netherlands

\begin{abstract}
Decisions about flood risk management are usually based on the reduction in flood risk compared to the implementation costs of the strategy. It is common practice to express flood risk (the combination of flood probabilities and potential flood damages) into a single number. The downside of this approach is that explicit information about how the system responds to the whole range of possible discharges is lacking. This type of information is relevant when a robust system is desired. We consider robust (fluvial) flood risk systems to have the ability to remain functioning under a range of river discharges. To understand system robustness, it is thus useful to analyze how the flood impact varies over a range of possible events. We applied a method to quantify the robustness of flood risk systems on a fluvial flood risk system in the Netherlands: the IJssel River, a branch of the Rhine River, and its flood-prone area. We compared four alternative system configurations of the IJssel River Valley, and analyzed their robustness, applying the following criteria: resistance threshold, response severity, proportionality and recovery threshold. The robustness analysis provides us with clues about how to enhance a flood risk system's robustness. We found that a system with unbreachable embankments scores best on overall robustness, because it has the least uncertain resistance threshold, the most proportional damage increase with increasing discharge, and the least uncertainty about where and when floods will occur. This shows that a robustness perspective helps to develop strategies that reduce the flood risks without increasing the consequences of beyond-design floods.
\end{abstract}

\section{INTRODUCTION}

Modern flood risk management not only relies on flood defenses, but also considers measures to reduce the vulnerability (Hall \& Solomatine 2008). Increased policy focus on vulnerability, as one of the components of flood risk, is triggered by recent disasters in for example New Orleans in 2005 and Japan in 2011, both unexpected events that exceeded the protection standards. Despite these events and the fact that risks primarily increase due to population growth and economic development in floodprone areas, many countries organize flood risk management around flood defenses with a protection standard.

Flood risk or expected annual damage, quantified by the combined probabilities and consequences of all possible flood events in a region, is an effective decision criterion to compare different types of measures, from strengthening embankments to land use planning. However, the use of a single risk estimate as decision criterion has also been criticized for a number of reasons:
1. It may not meet the decision needs of all stakeholders (Downton et al. 2005);

2. It assumes risk neutrality, while the public is generally risk averse (Merz et al. 2009);

3. Risk is uncertain, since many assumptions are needed to calculate risk, especially for systems with an extremely high protection standard (as in the Netherlands);

4. It hides information about the potential consequences of events that exceed the protection standards.

The main concern with using risk analysis in decision-support is how to deal with uncertainty. Downton et al. (2005) argue that practitioners should communicate better about uncertainties in estimates and how they are handled in developing strategic alternatives, whereas others focus on developing quantitative uncertainty analysis methods in support of flood risk management (Hall \& Solomatine 2008). The presence of uncertainty may be a reason to consider additional decision criteria besides the singlevalue flood risk estimate, for example the severity, duration and controllability of the risk (Stirling 
1998). In addition, some authors propose taking into account worst-case scenarios (Merz et al. 2010) or start so-called 'possibilistic thinking' instead of 'probabilistic thinking' (Clark 2005). Thus, in addition to the traditional comparison of flood risk and costs, it is advocated to analyse 'what if' design conditions are exceeded.

In literature on socio-ecological systems, the proposed way to deal with uncertainties is to aim for a robust or resilient system, instead of trying to control external disturbances. Among other things, control means that the variability of the system is reduced to make its behaviour better predictable: floods hardly happen. However, the downside of too much control is that unanticipated events may cause surprise and crisis (Holling 1996): when a flood does happen it will be a disaster. The idea of steering on system persistence (thereby allowing disturbances) instead of system stability was first introduced by Holling (1973) for ecosystem management, and later extended to the management of socio-ecological systems (Carpenter et al. 2001, Walker \& Salt 2006, www.resalliance.org). This type of management is called 'resilience'. In the field of flood risk management, however, the term resilience is associated with the ability to recover from the response to a disturbance (De Bruijn 2005), which is a narrower interpretation than that of the ecological and socioecological literature. To avoid confusion, we use the term system robustness for the ability to remain functioning under a range of possible disturbance magnitudes (see also Mens et al. 2011).

In this paper, we analyse robustness of a socioeconomic system to river flood waves, by providing insight into the system response to a range of river flood waves, including the extreme ones. From such an analysis, not only the level of protection but also the potential consequences of all possible discharge waves, and the balance between them, will become clear.

This 'robustness perspective' fits well in the recent policy developments on flood risk management in the Netherlands. In 2009, the Dutch government introduced what is referred to as a multi-layered approach to sustainable flood risk management, which states that three layers are required to manage flood risk in the long term: 1) flood defenses to protect against flooding, 2) spatial planning to limit the flood consequences, and 3) well-organized emergency management (National Government 2009). However, this multi-layered approach does not yet have any official status.

The idea of using system robustness as decision criterion in addition to damage risk, fatality risk and costs, was already tried out in De Bruijn et al. (2008) and Klijn et al. (2012), but only in a qualitative manner. In this paper, we compare alternative system configurations for the IJssel River Valley (a branch of the Rhine River) in the Netherlands, based on quantified robustness criteria. We apply the method as introduced in Mens et al. (2011) and adjusted in Mens \& Klijn (in prep.). The following criteria together provide an indication of system robustness (see Figure 1):

- Resistance threshold, or the smallest river discharge that will cause substantial economic damage;

- Response severity, or the flood damage in absolute terms;

- Response proportionality, or the sensitivity of the response to changes in discharge;

- Recovery threshold, or the discharge that will cause unmanageable flood disasters.

In addition, the uncertainty about the resistance threshold and the response severity should be indicated; the larger the uncertainty about these aspects, the lower the system robustness. The fourth criterion, recovery threshold, points at some critical level of damage from which recovery will be very difficult. Quantification of the discharge at which this critical threshold will be exceeded (the point of no recovery) requires insight into the flood damage relative to some maximum damage value or totalloss value. Analysing this is beyond the scope of this paper.

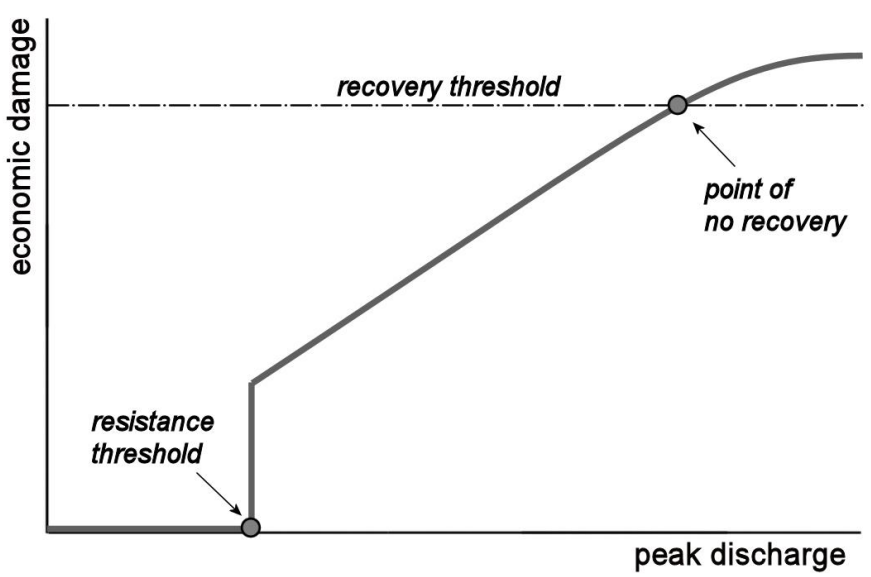

Figure 1. Theoretic response curve of a flood risk system (adapted from Mens et al. 2011)

\section{IJSSEL FLOOD RISK SYSTEM AND ALTERNATIVES}

We consider a flood risk system as the combination of physical and socio-economic characteristics of a region exposed to floods. In this case, we study the IJssel River and its flood-prone area: the IJssel Valley. The flood-prone area consists of 6 dike-ring areas (see figure 2). Each dike-ring area is protected from flooding by a closed ring of flood defenses and 
adjacent high grounds, which are designed to withstand river flood waves that occur on average once in 1250 years.

In view of climate change, the Netherlands government has started a national 'Delta Programme' to develop a long-term strategy for flood and drought risk management (Delta Programme 2011a). One of the programme's focal areas is the Rhine River delta, including the IJssel Valley. For the Rhine River, the design discharge (i.e., corresponding to a one in 1250-year flood wave) is expected to increase from $16000 \mathrm{~m}^{3} / \mathrm{s}$ to $18000 \mathrm{~m}^{3} / \mathrm{s}$ in the coming 50 100 years. Potential strategies include embankment heightening, giving more room to the river (to make sure the design water levels will not change and consequently the embankments do not need to be raised), unbreachable embankments, and combining embankments with spatial planning regulation (following the 'multilayered safety approach') (Delta Programme 2011b).

The future discharge of the IJssel River is uncertain, because of uncertain climate change and because the distribution of water over the three Rhine River branches is uncertain. Other relevant uncertainties are the flood wave shape (narrow or wide), the strength of the embankments and the location of embankment breaches. These sources of uncertainty influence the probability and consequences of flooding. Therefore, it is relevant to evaluate proposed strategies on how the adapted system will deal with a range of discharges, instead of optimizing the strategy for just one design discharge.

We analysed several alternative system configurations, to explore what enhances the system robustness to flood waves. A configuration is the combination of river hydraulics, embankment location and strength, and land use. The reference system is as close as possible to the real situation of 2015, except for the land use. A land use map of the year 2015 was not available; instead, we used one of the year 2000. Each dike-ring area has an assumed flood probability of $1 / 1250$ per year. We compared the following alternative configurations with the reference system:

1. CE Conventional Embankments: embankments are raised with a $\Delta \mathrm{h}$ (locationdependent) that corresponds to a change in discharge from $\mathrm{T}=1250$ to $\mathrm{T}=5000$;

2. RR Room for the River: the floodplains are lowered such that the water level at the current design discharge is reached at a higher discharge. The $\Delta \mathrm{Q}$ is about $300 \mathrm{~m}^{3} / \mathrm{s}$, which corresponds to the change in discharge in $\mathrm{CE}$;
3. UE1 Unbreachable Embankments, version 1: all embankments are strengthened (not raised) such that they become unbreachable. Water may, hence, flow over the flood defense and still cause flood damage;

4. UE2 Unbreachable Embankments, version 2: like UE1, but embankments near cities are raised with $0.5 \mathrm{~m}$.

We assume that unbreachable embankments will never fail. In practice, it may be difficult or at least expensive to construct an embankment of which the probability of structural failure and thus breaching can be neglected. We use 'neglected', because a zero failure probability is geotechnically impossible. Currently, conventional embankments in the Netherlands have design criteria for each failure mechanism. The failure probability due to overflow, at design conditions, should be less than $10 \%$ of the design standard. Other failure mechanisms than overflow are also allowed a maximum of $10 \%$ of the design exceedance probability. Unbreachable embankments can be defined as embankments for which the design criteria are a factor 100 stricter, so that they also withstand conditions beyond design (see also De Bruijn et al. 2012). This means, for dike-ring areas with a design standard of 1/1250 per year, that the probability of failure of an embankment due to overflow at design conditions is smaller than 1/1.250.000 per year. Therefore, we feel that the failure probability (in the meaning of breaching) may be neglected. However, further research is needed to explore the technical possibilities and costs of changing a conventional embankment into an unbreachable one.

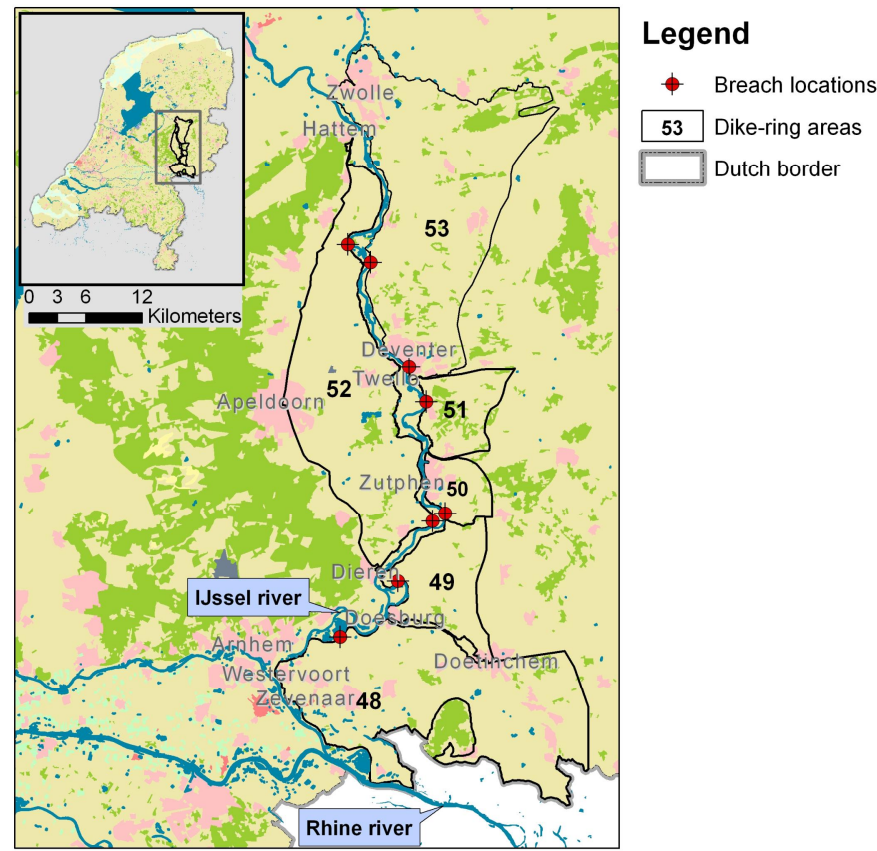

Figure 2. IJssel Valley study area with dike-ring areas and breach locations indicated 


\section{QUANTIFICATION OF SYSTEM ROBUSTNESS}

\subsection{Estimating economic damage}

Quantifying system robustness starts by constructing a so-called response curve: a relationship between the flood damage and the peak discharge (Mens et al. 2011), from which the robustness criteria can be derived. To estimate monetary flood damage, we used the 2-dimensional hydrodynamic flood simulation model Delft-FLS (WL 2001) and the economic damage model DamageScanner (Klijn et al. 2007).

Figure 3 shows the simulated flood waves. We chose three different peaks with each three different wave shapes. The wave IDs refer to the corresponding discharge at Lobith, where the Rhine River enters the Netherlands, divided by $1000 \mathrm{~m}^{3} / \mathrm{s}$. Thus, L16 corresponds to a discharge of $16000 \mathrm{~m}^{3} / \mathrm{s}$ at Lobith. L14 was chosen because there is a small probability that embankments fail at lower dicharges than the design conditions. For the alternative systems with unbreachable embankments, two additional flood peaks were needed (L17 and L18). For these systems, no damage is expected for the lowest two flood waves (L14 and L16), since embankments are assumed not to breach and are modelled as high as the maximum water level L16 (design discharge).

For the flood simulations, we selected eight representative breach locations: one for each dike-ring area and two for the larger ones (numbers 52 and 53 in Figure 2). The economic damage that occurs due to a dike breach at these locations is considered representative for the area; this means that it should be comparable to the economic damage averaged over a large set of breach locations within one dike-ring area. The dikes are assumed to breach when the local water level reaches its peak (for waves with $\mathrm{Q}_{\text {peak }}<2560 \mathrm{~m}^{3} / \mathrm{s}$ ), or when the design local water level is exceeded (for waves with $Q_{\text {peak }}>2560 \mathrm{~m}^{3} / \mathrm{s}$ ). The design discharge is $2560 \mathrm{~m}^{3} / \mathrm{s}$. We modelled the breach width as an exponential function of time; within 50 hours a breach width of $200 \mathrm{~m}$ is reached. The maximum depth, which is equal to embankment height minus land elevation, is reached in the first hour from the start of the breach.

For the alternative system configurations, we needed additional assumptions. For conventional embankments, the amount by which the embankments were heightened $(\Delta h)$ was derived from the frequency curve of local water levels. We combined the stagedischarge relationship at each location (known from the model calculations) with the discharge-frequency curve of the IJssel River. The latter was derived from the discharge-frequency curve for the Rhine
River at Lobith (Thonus et al. 2003) assuming that $16 \%$ of the discharge diverts to the IJssel River. The effect of this assumption is discussed in Mens \& Klijn (in prep.). We substracted the water level at $\mathrm{T}=5000$ years from the water level at $\mathrm{T}=1250$ years, which resulted in a $\Delta \mathrm{h}$ of $15-20 \mathrm{~cm}$ depending on the location.

For alternative RR ('room for the river'), the stagedischarge relationship was adapted by $300 \mathrm{~m} 3 / \mathrm{s}$ (see Figure 4), assuming that the effect will be equal for all discharges. In reality, the effect will be zero for discharges below a certain threshold, but since for these low discharges dike breaches are not expected, no damage was calculated. The assumption thus does not influence the results of this paper.

For UE ('unbreachable embankments') we assumed embankment heights corresponding to the standard L16 flood wave, which corresponds to the design discharge. For UE2, the embankments near urban areas were raised with $0.5 \mathrm{~m}$. The stage-discharge relationship remained unchanged.

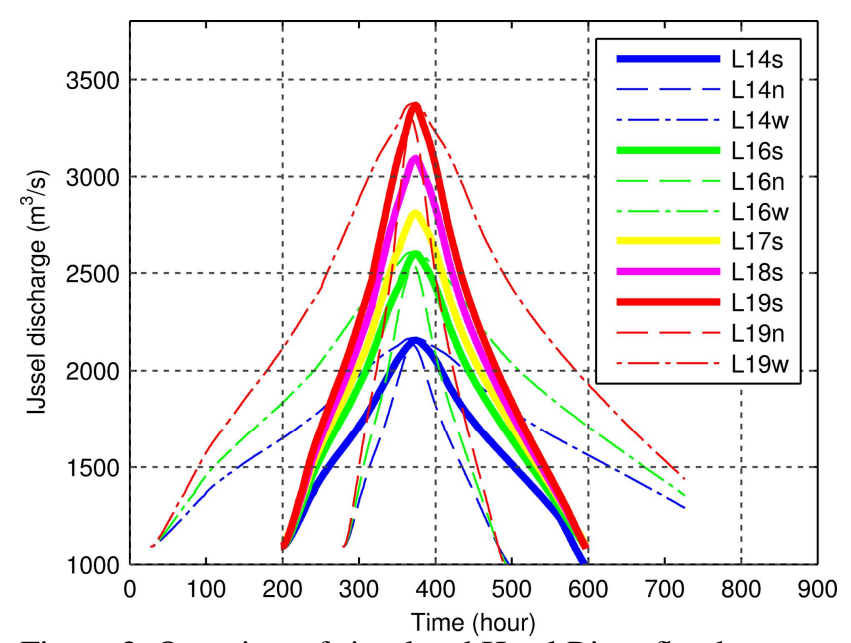

Figure 3. Overview of simulated IJssel River flood waves

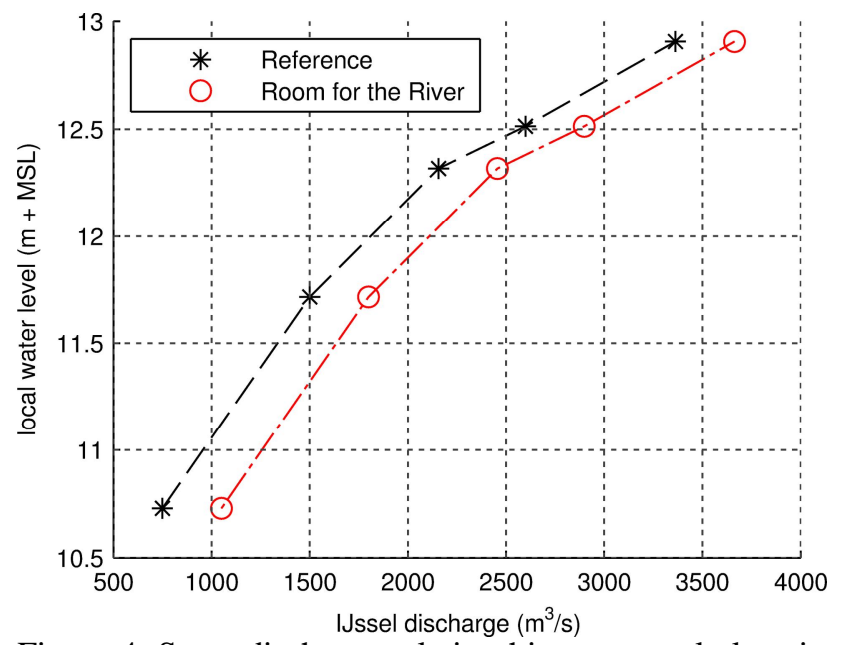

Figure 4. Stage-discharge relationship at example location, for reference and for room for the river 


\subsection{Response curves}

To obtain the response curve for the entire river valley, the damages of all breach locations had to be combined. However, because of the uncertainty about embankment strength, it is unknown which embankment will breach first. Many combinations are possible, each with a different damage estimate. It is hydraulically impossible to have all eight breaches occurring within one flood wave, simply because there is not enough water to flood the entire system. Therefore, we summed the damages of two to four breach locations in all possible combinations. Assuming that each combination has an equal probability of occurrence, and following a MonteCarlo approach, we derived box plots of the damage for each flood wave. Figure 5 shows the result for the reference system. When one or more embankments fail, the damage is estimated between 0.3 and 31.4 billion Euro (depending on wave height, wave shape and breach locations). It also becomes clear that a wider flood wave shape causes a significant increase of the damage. This means that the system is sensitive for both the discharge peak and the discharge shape. Furthermore, the uncertainty about the breach location makes it very difficult to estimate what exactly will happen during a particular flood wave.

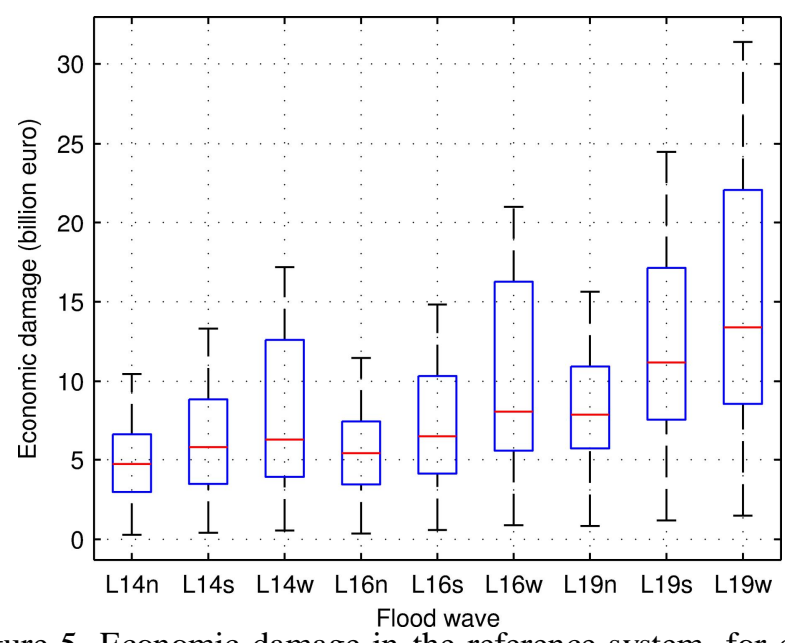

Figure 5. Economic damage in the reference system, for each simulated flood wave ( $\mathrm{n}=$ narrow, $\mathrm{s}=$ standard, $\mathrm{w}=$ wide), and uncertainty resulting from different breach combinations. Red line indicates the median, the box indicates the upper and lower quartiles, and the whiskers indicate the minimum and maximum value of the model output.

To compare the response curves of alternative system configurations (Figure 6), we assumed a standard wave shape and the median damage of all possible breach combinations. The vertical lines indicate the design discharge. Although it is uncertain at what discharge a breach will occur, it is clear that the curve will suddenly increase from zero to significant damage when one or more embankments fail. Beyond that 'critical' discharge, the damage increases with an increasing discharge peak.

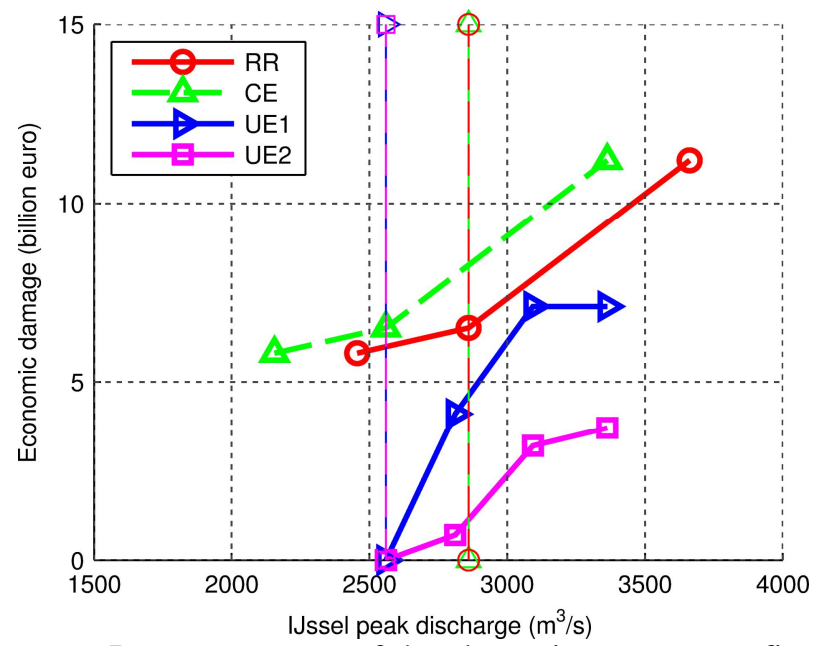

Figure 6. Response curves of the alternative system configurations, and the design discharges indicated with vertical dashed lines

\subsection{Robustness criteria}

The robustness criteria were derived from the response curves and the boxplots for each alternative system configuration. Next, we explain the scores for each criterion. Table 1 provides an overview of robustness scores.

To indicate the resistance threshold, i.e. the lowest discharge causing damage, we used the design discharge. The reference system has a design discharge of $2560 \mathrm{~m}^{3} / \mathrm{s}$ (T=1250 years), just as UE1 and UE2. The configurations $\mathrm{CE}$ and RR have a higher design discharge of $2560+300 \mathrm{~m}^{3} / \mathrm{s}(\mathrm{T}=5000$ years). The design discharges are indicated with the vertical dashed lines in the response curves of Figure 6 . We note that the actual resistance threshold is uncertain, since the embankment strength is uncertain; the lowest discharge causing damage may well be lower or higher than the design discharge. This is not the case for UE1 and UE2. Because for these cases zero failure probability was assumed, the discharge causing damage only depends on the height of the embankment instead of both height and strength. We consider the height of the embankments well-known in the Netherlands, so the level of uncertainty about the resistance threshold is much lower for unbreachable embankments.

The response severity is indicated by the median of the economic damage as a result of discharge wave L19s (the highest flood wave that was simulated, with a standard shape). The choice of L19 is underpinned as follows. The aim is to show the difference in absolute damage between system configurations as a result of an extreme discharge wave. Lower discharges were only simulated for the unbreachable embankment alternatives (L17 and L18), or do not cause any damage in UE1 and UE2 (L14 and L16). 
The level of uncertainty about this value (due to breach combinations and wave shape) was scored separately, using the boxplots explained in section 3.2. We used the minimum value (smallest damage resulting from the narrow wave shape) and the maximum value (highest damage resulting from the wide wave shape) of flood wave L19, given in percentage difference from the median of the standard shape.

The robustness criterion 'proportionality', indicating the sensitivity of the damage for changes in discharge, was scored by visually comparing the response curves of Figure 6. We ranked them based on the damage at the resistance threshold and the steepness of the curve. The alternative with the largest change in damage and the steepest curve receives a score of 1 (low proportionality); the alternative with the smallest change in damage and the flattest curve receives a score of 4 (high proportionality).

The largest difference is found in the damage at the resistance threshold. When embankments fail at the resistance threshold, suddenly large damages occur in CE and RR. In UE1 and UE2 this damage is close to zero. Thus, CE and RR score 1 or 2, and UE1 and UE2 score 3 or 4 . The response curves of CE and $\mathrm{RR}$ are equally steep, but the sudden increase in damage of CE is larger. Therefore, CE scores 1 and RR scores 2. The response curve of UE2 is clearly less steep than that of UE1, therefore UE2 receives the highest score 4.

Table 1. Overview of robustness scores of all system configurations. Colours indicate for each criterion the lowest score (red) and the highest score (green) in terms of robustness.

\begin{tabular}{|c|c|c|c|c|c|}
\hline \multirow[t]{2}{*}{ Robustness criterion } & \multirow[t]{2}{*}{ Dimension } & \multirow{2}{*}{$\begin{array}{c}\begin{array}{c}\text { Conventional } \\
\text { dikes }\end{array} \\
\mathrm{CE} \\
\end{array}$} & \multirow{2}{*}{$\begin{array}{c}\begin{array}{c}\text { Room for the } \\
\text { river }\end{array} \\
\text { RR } \\
\end{array}$} & \multicolumn{2}{|c|}{ Unbreachable Embankments } \\
\hline & & & & UE1 & UE2 \\
\hline Resistance threshold & $\mathrm{m} 3 / \mathrm{s}$ & 2860 & 2860 & 2560 & 2560 \\
\hline level of uncertainty & - & high & high & low & low \\
\hline Response severity & Beuro & 11.2 & 9.3 & 7,1 & 3,7 \\
\hline level of uncertainty & $\%$ & $-95-180$ & $-95-190$ & $-50-95$ & $-70-130$ \\
\hline Proportionality & rank nr. & 1 & 2 & 3 & 4 \\
\hline
\end{tabular}

\section{DISCUSSION OF ROBUSTNESS SCORES}

The aim of this paper was to compare alternative system configurations on their robustness to flood waves. Here we discuss the robustness scores for each system configuration.

The systems with unbreachable embankments (UE1 and UE2) score best on all robustness criteria except the resistance threshold. The flood damage for discharges that exceed the resistance threshold is lower than that of all other configurations, and it increases proportional to the discharge increase. This is because water flows over the embankment without breaching the embankment, resulting in significantly less floodwater. Although the resistance threshold is slightly higher than that of the other configurations, there is little uncertainty about it. Differently stated: a lower resistance threshold is acceptable, because the uncertainty is small. The uncertainty about the response is smaller as well. This is because the uncertainty about where embankments will breach is eliminated, since the probability of breaching is negligible. A reduction of uncertainty implies that it can be better predicted when and where floods are to be expected. The remaining uncertainty is due to the shape of the discharge wave.

The system with room for the river (RR) also has a lower flood damage for all discharges above the resistance threshold (compared to $\mathrm{CE}$ ), but the reduction is less than that of unbreachable embankments. Moreover, a flood may still cause an unmanageable situation.

The system with conventionally-raised embankments (CE) increases the resistance threshold (compared to the reference), but consequently reduces the proportionality. This means that it appears to be safer, because higher discharges are needed to cause flooding, but once the embankments fail the flood will be unmanageable to a larger degree than in the reference and in RR. In terms of uncertainty and proportionality, CE scores comparable to RR.

The system with unbreachable embankments type 2 (higher embankments near urban areas) further reduces the flood damage and increases the proportionality. This shows that if it is possible to build unbreachable embankments, it is beneficial to prioritize locations based on potential damage and casualties. 


\section{CONCLUSION}

A risk approach a key to modern flood risk management, but for deciding about the most desirable system configuration in view of uncertain discharges, a robustness perspective may be of added value. We analysed the flood consequences of the IJssel Valley in terms of economic damage for four alternative system configurations. Based on the results, we conclude that the following characteristics enhance system robustness of the IJssel Valley:

- Limited uncertainty about where, when and how embankments will fail. If a flood is better predictable, it is better manageable and as such it increases the system robustness. This can be achieved by building unbreachable embankments, preferably differentiated in height.

- Good balance between a high resistance threshold and yet a relatively low flood damage. This can be achieved by ensuring a limited difference between design water levels and the elevation of the protected area. The case study showed that it is possible (e.g., by giving room to the river) to increase the design discharge without increasing the potential damage, whereas just raising dikes does increase the potential damage.

Other characteristics that positively influence the robustness include (not studied in this paper):

- Critical infrastructure (such as major roads, power supply, hospitals and food supply) in higher areas (Wardekker et al. 2010);

- A controlled breach process, for example by structures that limit the breach growth;

- Flood-proof buildings and infrastructure;

- Compartments that limit the flood extent and thereby reduce the flood consequences (Klijn et al. 2009).

Of all studied alternative configurations of the IJssel Valley, the one with unbreachable embankments (type 2) increases the robustness most. However, there are practical limitations to construct unbreachable embankments, such as costs and available space. The most effective locations could be selected based on casualty reduction relative to marginal costs (De Bruijn et al. 2012).

We feel that these conclusions apply to all embanked river valleys with a natural relief, and with hydraulic system behaviour. Hydraulic system behaviour ensures that, when water flows over the embankments at one location, water levels elsewhere will be lowered. Measures that reduce the water level (like giving room to the river) will be extra effective in areas where the stage-discharge relation is steep, thus where an increase in discharge causes a large increase in water level. This is regularly the case near large cities. Unbreachable embankments will have a limited effect on robustness in small polder areas that will fill up very quickly, causing large water depths and thus casualties and damage.

We conclude that a robustness perspective makes explicit what happens if protection standards are exceeded. It thus helps in developing strategies that reduce the flood risks without increasing the consequences of beyond-design floods.

\section{ACKNOWLEDGEMENTS}

The research described in this paper was funded by the Knowledge for Climate research programme (http://knowledgeforclimate.climateresearchnetherla nds.nl/) and the Delta Programme Rivers.

\section{REFERENCES}

Carpenter, S., Walker, B., Anderies, J. M., \& Abel, N. 2001. From metaphor to measurement: resilience of what to what. Ecosystems, 4, 765-781.

Clarke, L. 2005. Worst-Case Thinking: An Idea Whose Time Has Come. Natural Hazards Observer. Natural Hazards Centre, Colorado.

De Bruijn, K. M. 2005. Resilience and flood risk management. A systems approach applied to lowland rivers. Delft: Technical University Delft.

De Bruijn, K. M., Mens, M. J. P., \& Klijn, F. 2008. A method for developing long-term strategies for flood risk management. In: Samuels, P., Huntington, S., Allsop, W., \& Harrop, J., eds. Flood Risk Management Research into practice. Oxford: CRC Press.

De Bruijn, K. M., Knoeff, J. G. \& Klijn, F. 2012. Unbreachable embankments? In pursuit of the most effective stretches for reducing fatality risk. Proceedings of FLOODrisk2012 (this volume)

Delta Programme 2011a. Delta Programme 2012: Taking measures now, preparing for tomorrow (in Dutch). Ministry of Infrastructure and Environment \& Ministry of Economic Affairs, Agriculture and Innovation. The Hague.

Delta Programme 2011b. Delta Programme 2012: Taking measures now, preparing for tomorrow. Appendices (in Dutch). Ministry of Infrastructure and Environment \& Ministry of Economic Affairs, Agriculture and Innovation. The Hague.

Downton, M. W., Morss, R. E., Wilhelmi, O. V., Gruntfest, E., \& Higgins, M. L. 2005. Interactions between scientific uncertainty and flood management decisions: Two case studies in Colorado. Global Environmental Change Part B: Environmental Hazards, 6(3), 134-146. 
Hall, J., \& Solomatine, D. 2008. A framework for uncertainty analysis in flood risk management decisions. International Journal of River Basin Management, pp. 85-98.

Holling, C. S. 1973. Resilience and stability of ecological systems. Annual Review of Ecology and Systematics, 4, 1-23.

Holling, C. S. 1996. Engineering resilience versus ecological resilience. In: Schulze, P., ed. Engineering within ecological constraints. Washington: National Academy.

Klijn, F., P. Baan, K.M. de Bruijn, and J. Kwadijk. 2007. Flood risks in the Netherlands in a changing climate; expectations, estimates and calculations for the 2nd sustainability outlook for the Netherlands (in Dutch). Delft Hydraulics report Q4290, Delft.

Klijn, F., Asselman, N., \& Van der Most, H. 2009. Compartmentalisation: flood consequence reduction by splitting up large polder areas. Journal of Flood Risk Management, 3(1), 3-17.

Klijn, F., Knoop, J., Ligtvoet, W., \& Mens, M. 2012. In search of robust flood risk management alternatives for the Netherlands. Nat. Hazards Earth Syst. Sci., 12(5), 1469-1479.

Mens, M. J. P., Klijn, F., de Bruijn, K. M., \& van Beek, E. 2011. The meaning of system robustness for flood risk management. Environmental Science \& Policy, 14(8), $1121-1131$

Mens, M.J.P. \& Klijn, F. In prep. Comparing flood risk and system robustness of the IJssel River Valley. Journal paper in preparation.

Merz, B., Elmer, F., \& Thieken, A. H. 2009. Significance of "high probability/low damage" versus "low probability/high damage" flood events. Nat. Hazards Earth Syst. Sci., 9(3), $1033-1046$

Merz, B., J.Hall, M.Disse, \& A.Schumann 2010. Fluvial flood risk management in a changing world. Natural Hazards and Earth System Sciences, 10, 509-527.

National Government 2009. National Waterplan: A safe and liveable delta, today and in the future. Dutch Ministry of Infrastructure and Environment \& Dutch Ministry of Economic Affairs, Agriculture and Innovation. Deventer: Thieme.

Stirling, A. (1998). Risk at a turning point? Journal of Risk Research, 1(2), 97-109.

Thonus, B., Diermanse, F., \& Lammers, I. 2003. Flood Risks and Safety in the Netherlands : Hydraulic boundary conditions phase 2 (in Dutch). Delft: WL | Delft Hydraulics.

Walker, B., \& Salt, D. 2006. Resilience Thinking: Sustaining Ecosystems and People in a Changing World. Washington: Island Press.

Wardekker, J. A., de Jong, A., Knoop, J. M., \& van der Sluijs, J. P. 2010. Operationalising a resilience approach to adapting an urban delta to uncertain climate changes. Technological Forecasting and Social Change, 77(6), 987-998.

WL 2001. Manual Delft-FLS 2.55. Delft: WL | Delft Hydraulics. 